\title{
TRATAMIENTOS HONORÍFICOS, REFERENCIALES Y SOCIEDAD. LAS FÓRMULAS DE TRATAMIENTO EN EL ESPAÑOL DE BUENOS AIRES DE LA ETAPA COLONIAL: ENTRE LA CORTESÍA Y EL PODER
}

\author{
Honorifics, referential address forms and society. Forms of address in Buenos Aires \\ Spanish of the colonial period: between politeness and power
}

\author{
Elizabeth Rigatuso* \\ Universidad Nacional del Sur \\ elizabeth.rigatuso@uns.edu.ar
}

\section{Palabras clave \\ tratamientos honoríficos; fórmulas de tratamiento referenciales;} (des)cortesía colonial; asimetrías de poder; español de Buenos Aires

\footnotetext{
Keywords

honorifics;

forms of reference; colonial (im)politeness; power asymmetries; Buenos Aires spanish
}

\begin{abstract}
RESUMEN
Los estudios históricos sobre el Buenos Aires colonial señalan la existencia de un complejo entramado social estamental, que se sustentaba básicamente en jerarquías de orden étnico. Esta jerarquía legitimaba el status de la población blanca de origen español y se ubicaban luego, con privilegios marcadamente descendentes, los no blancos, las llamadas castas, integradas por pobladores de pueblos originarios, de etnias africanas y nacidos de fusiones étnicas (Areces, 2000, Beato, 2005; v. también Presta, 2000). En ese marco, las fórmulas de tratamiento eran reflejo y expresión de diversas actitudes sociales, operando, como valiosos elementos discursivos de construcción y negociación de identidades, y de marcación de las asimetrías existentes (Rigatuso, 2008; Rojas Mayer, 2008). El presente artículo se centra en dos fenómenos del sistema de tratamientos de entonces que presentan especial interés sociolingüístico y pragmático por su funcionalidad para la expresión de dichas asimetrías: a) los tratamientos corteses, en especial los Tratamientos Honorificos (Lapesa, 1970), que promueven una focalización deferente de interlocutores y referidos (Haverkate, 1994), y b) los usos nominales referenciales empleados para aludir a los miembros de los diferentes grupos humanos. En las producciones del grupo dominante, ambas modalidades de tratamiento constituyen estrategias discursivas complementarias que gestionan, subrayan y expresan esas desigualdades, contribuyendo a la construcción y proyección de la imagen social de ese grupo social. La investigación se adscribe a los estudios de Sociolingüística (Romaine, 1982; Nevalainen/Raumolin-Brunberg, 2005; Hernández-Campoy/Conde-Silvestre, 2012) y Pragmática históricas (Jucker/Kopaczyck, 2017), con aportaciones de Sociopragmática, Pragmática Sociocultural (Bravo/Briz, 2004) y Análisis del Discurso (Van Dijk, 2000). El corpus textual está integrado por fuentes institucionales y no institucionales.
\end{abstract}

\begin{abstract}
Historical studies on colonial Buenos Aires indicate the existence of a complex social fabric that was mainly based on ethnic hierarchies. This hierarchy legitimized the status of the white population of Spanish origin and then, with markedly descending privileges, the non-whites, the so-called castes, made up of the inhabitants of original peoples, of African ethnicities and born of ethnic fusions were located (Areces, 2003, Beato, 2005; v. also Presta, 2000). In this framework, address forms were a reflection and expression of diverse social attitudes, operating as valuable discursive elements of construction and negotiation of identities, and marking of existing asymmetries (Rigatuso, 2008; Rojas Mayer, 2008). This article focuses on two phenomena of the colonial address forms that present special sociolinguistic and pragmatic interest due to their functionality for the expression of those asymmetries: a) politeness forms of address, especially Honorifics (Lapesa, 1970), that are used as forms of deference toward interlocutors and the third persons (Haverkate, 1994), and b) the referential nominal forms used to refer to the members of the different human groups. In the productions of the dominant group, both address modalities constitute complementary discourse strategies that manage, highlight and express these inequalities, contributing to the construction and projection of the social image of that social group. The research uses the frame of Historical Sociolinguistics (Romaine, 1982; Nevalainen/Raumolin-Brunberg, 2005; Hernández-Campoy/ Conde-Silvestre, 2012) and Historical Pragmatics (Jucker/Kopaczyck, 2017), but it also builds on Sociopragmatics, Sociocultural Pragmatics (Bravo/Briz, 2004) and Discourse Analysis (Van Dijk, 2000). The corpus analysed consists of institutional and non-institutional discourses.
\end{abstract}




\section{Introducción ${ }^{1}$}

Los estudios históricos sobre el Buenos Aires colonial señalan la existencia en la sociedad de entonces de un complejo entramado estamental, plasmado en un "mosaico de grupos" (Areces, 2000), que se sustentaba básicamente en la coexistencia de distintos grupos étnicos. En estas jerarquías de orden étnico, se legitimaba el status de la población blanca de origen español -europea y americana, esta última integrada por los llamados criollos-, a los que se agregaban algunos europeos no españoles, y se ubicaban luego, con privilegios marcadamente descendentes, los no blancos, las llamadas castas, integradas por pobladores indios, negros y pobladores producto de combinaciones étnicas (Beato, 2005; v. también Presta, 2000). ${ }^{2}$

En ese marco sociohistórico, la lengua era reflejo al mismo tiempo que expresaba diversas actitudes sociales de la época vinculadas a dicha estratificación, las que encontraban, a nivel de uso lingüístico, en las fórmulas de tratamiento, en sus distintas posibilidades de realización y conformación (Rigatuso, 2009), valiosos elementos discursivos de construcción de identidades (Gumperz, 1982; Joseph, 2004) y de marcación de las asimetrías existentes entre los miembros de la comunidad (Rigatuso, 2008; Rojas Mayer, 2008). Este hecho se ponderaba aún más cuando convergían en el grupo de los españoles y sus descendientes las jerarquías de orden étnico con jerarquías sociales de orden socioeconómico y/o basadas en jerarquías institucionales y administrativas, constituyendo la clase dirigente (v. Rojas, 1997; Maldonado, 2008).

En el presente trabajo abordaremos aspectos de esta cuestión, prestando particular atención a dos fenómenos que, en el conjunto de rasgos característicos del sistema de tratamientos de la época, presentaban especial interés por su funcionalidad para la expresión de dichas asimetrías: a) los tratamientos corteses, en especial los denominados Tratamientos Honorificos (Lapesa, 1970), que promueven una focalización deferente de interlocutores y referidos (Haverkate, 1994), ${ }^{3}$ y b) los usos nominales referenciales empleados para aludir a los miembros de los diferentes grupos humanos.

En las producciones del grupo dominante, ambas modalidades de tratamiento operaban -a partir del ensalzamiento deferente y cortés de unos y la ausencia de atribución de recursos de cortesía a otros, que llegaba en algunos casos a la desfocalización y/o despersonalización de destinatario o referente- como estrategias discursivas complementarias que gestionaban, subrayaban y expresaban las asimetrías y desigualdades existentes en la sociedad de la época. Junto a estos elementos, otros

1. Agradezco al Dr. Hugo Wingeyer y al equipo editorial de la revista Cuadernos de Literatura. Revista de Estudios Lingüisticos y Literarios su generosa invitación para participar en este número en Homenaje a Inés Abadía de Quant, destacada lingüista argentina, cuya labor investigativa ha arrojado luz de forma insoslayable a la realidad dialectal del español del Noreste argentino, en perspectivas históricas y sincrónicas, y, desde allí, al español de la Argentina en sus distintos rasgos constitutivos.

2. Este trabajo integra el proyecto del grupo de investigación "Variación pragmática y gestión interrelacional en la interacción verbal del español bonaerense. Uso y percepciones", subsidiado por la Secretaría de Ciencia y Tecnología de la Universidad Nacional del Sur. Resultados de un primer acercamiento al tema fueron presentados en el IX Congreso SOLAR "Desde el sur mirando a nuestra América".

3. Haverkate define el concepto de focalización como "una estrategia referencial que pone de relieve la identidad o el papel social del hablante o interlocutor" (1994, p. 216). 
fenómenos gramaticales, léxico-semánticos y pragmático-discursivos contribuían igualmente, desde la producción del discurso, a la expresión de dicha desigualdad, reflejando las condiciones sociohistóricas de esa producción.

El análisis se centrará en particular en las estrategias de inserción discursiva de los miembros de los distintos grupos humanos empleadas por parte de los hablantes pertenecientes al polo de mayor poder: los españoles y sus descendientes, poniendo especial atención en el contraste existente en los modos de autopresentación y de presentación de los otros, implementados por integrantes de ese grupo de la Colonia (Van Dijk, 2003). Asimismo, dadas las limitaciones en cuanto a fuentes al efectuar un estudio sociolingüístico del pasado de una lengua, ${ }^{4}$ este contraste se pondrá particularmente en evidencia en el uso de las fórmulas de tratamiento referenciales, a las que nos abocaremos en forma especial.

La investigación se adscribe a los estudios de Sociolingüística (Romaine, 1982, 1988; Nevalaine y Raumolin-Brunberg, 2005; Hernández-Campoy y Conde-Silvestre (2012) y Pragmática históricas (Ridruejo, 2002; Jucker y Kopaczyck, 2017), con aportaciones de Pragmalingüística (Haverkate, 1994), Sociopragmática (Spencer-Oatey, 2008) y Pragmática Sociocultural (Bravo y Briz, 2004; Kaul, 2008) para el abordaje de prácticas de (des)cortesía y gestión interpersonal. En este marco, operamos con los conceptos de imagen social de Goffman (1967), y de autonomía y afliación propuestos por Fant (1989) y desarrollados posteriormente por Bravo (1999, 2003), vinculados también a la imagen social. Según la propuesta de Bravo, la autonomía se relaciona con el hecho de "cómo una persona desea verse y ser vista por los demás como un individuo con contorno propio dentro del grupo", es decir, como alguien diferente del grupo, y la afiliación con "cómo desea verse y ser vista por los demás en cuanto a las características que lo identifican con el grupo" es decir, como alguien integrado en el grupo (Bravo, 2003, p. 106). Para el análisis de los tratamientos resulta fundamental, además, la dinámica de las clásicas dimensiones de poder y solidaridad (Brown y Gilman, 1960), que en diferentes comunidades lingüísticas pautan el uso de estos elementos lingüísticos, determinando esquemas de trato simétricos y asimétricos entre los hablantes. ${ }^{5}$ Por último, integramos a nuestro estudio contribuciones de Análisis Crítico del Discurso (Fairclough, 1989; Van Dijk, 2003).

El corpus de análisis está constituido por fuentes documentales institucionales y no institucionales, pertenecientes a tres subcorpus: las Cartas privadas de emigrantes a Indias (1540-1616) compiladas por Enrique Otte (1982), de las que hemos considerado las agrupadas bajo el rótulo Rio de la Plata, y los documentos correspondientes a Buenos Aires, seleccionados, transcriptos y compilados por Fontanella de Weinberg (1993) y Rigatuso y Suardíaz (2008), integrados por distintos tipos

\footnotetext{
4. No contamos hasta el presente con discursos que testimonien el uso directo por partes de los hablantes ubicados en el polo de menor poder - ni como hablantes ni en su rol interaccional de destinatarios. No obstante, estimamos que un nuevo rastreo de fuentes ofrecerá datos en tal sentido, en particular, la consulta de transcripciones de juicios de la época.

5. Más allá de ciertas limitaciones advertibles en el modelo propuesto, en especial desde una perspectiva pragmática, y de algunas valiosas revisiones críticas de sus postulados (véase, por ejemplo, Tannen, 1996), es conocida e innegable la relevancia que el trabajo de Brown y Gilman, con sus conclusiones respecto de la vigencia en la dinámica de los tratamientos de distintas comunidades del mundo de las dimensiones de poder y solidaridad, ha tenido en la investigación sociolingüística sobre el tema.
} 
discursivos. Entre ellos destacan: Acuerdos del Cabildo y de Real Hacienda, Bandos del Cabildo, donaciones de tierras, padrones, cartas y recibos de dote, testamentos, otorgamiento de poderes, cartas y notas de autoridades administrativas y eclesiásticas a la corona, documentación judicial, y correspondencia familiar, social y comercial. Todos ellos corresponden a la etapa comprendida entre los siglos XVI y XVIII, período histórico que aborda el presente estudio, y nos muestran, en realidad, desde el punto de vista del productor del discurso, las estrategias discursivas de construcción de identidad y asimetrías desde uno de los grupos: los españoles y sus descendientes.

En cuanto a estudios previos, la revisión bibliográfica muestra valiosos trabajos históricos que abordan cuestiones vinculadas al tema en distintas variedades del español de América. En Las formas de tratamiento nominales usadas por y para la población de origen africano en Montevideo en los siglos XVIII y $X I X$ (2011), dentro de la dinámica de las dimensiones de poder y solidaridad (Brown y Gilman, 1960) centrada en el vínculo de amo y esclavo, Magdalena Coll realiza un análisis detenido de las fórmulas de tratamiento empleadas por la población de origen africano y las dispensadas hacia esa población en el Montevideo de los siglos XVIII y XIX. Por su parte, en Identidad, imagen y (des)cortesía en Cartagena de Indias (siglo XVII). Diálogos surgidos desde el enfrentamiento étnico (2015) Micaela Carrera de la Red se centra en actividades de imagen, identidad y prácticas de descortesía en intercambios comunicativos contenidos en un juicio celebrado en la ciudad de Cartagena de Indias hacia fines del siglo XVII, en un contexto de conflicto interétnico de la sociedad esclavista colonial, dando cuenta -entre otros aspectos considerados- de cuestiones referidas a las fórmulas de tratamiento vinculadas a la población de origen africano. En cuanto a los miembros de los pueblos originarios, en el artículo de Patricia Vallejos (1994) Aspectos del léxico de los siglos XVI y XVII en dos regiones americanas, se recogen referencias al modo de designación de los integrantes de la población indígena en documentos coloniales del español de la región rioplatense de los siglos XVI y XVII.

Los antecedentes más directos de nuestra investigación lo constituyen los estudios de Elena Rojas Mayer sobre los tratamientos referenciales en los documentos coloniales americanos, considerados como modo de expresión de "la composición humana del mundo hispanohablante de la época” (1997, p. 127), con especial atención al español de la Gobernación del Tucumán. La autora destaca la importante información sociolingüística que proporcionan los tratamientos sobre los grupos humanos de la época, vinculada con su rol como representaciones sociales (Rojas Mayer, 1997, 1998, 2008, 2011). En relación con el tema de las representaciones sociales, resulta importante también la tesis doctoral de Silvia Maldonado (2009) sobre el mismo espacio geográfico y administrativo, y, en perspectiva similar a la planteada por Rojas Mayer, su artículo Las fórmulas de tratamiento en el ámbito administrativo hasta el siglo XIX (2008), en el que se ocupa de las denominaciones de persona en el dominio administrativo colonial. Por último, personalmente abordamos algunos aspectos referidos a las asimetrías bajo estudio en los artículos De vecinos $y$ moradores. Tratamientos referenciales y voces para el hombre en la lengua de Buenos Aires de la etapa colonial (Rigatuso, 2008) y Expresión de interculturalidad y contacto de culturas en el sistema de tratamientos del español bonaerense (Rigatuso, 2012), este último en una perspectiva diacrónica variacional del español bonaerense que parte de la época colonial y llega hasta mediados del siglo XX. 
A esta línea de estudios se adscribe el presente artículo, en el que, lejos de pretender exhaustividad, se realiza un primer acercamiento de conjunto, de carácter exploratorio, a la expresión sociolingüística de las desigualdades étnicas y sociales referidas en la lengua del Buenos Aires colonial, a partir de fenómenos de variación pragmático-discursiva centrados en el uso de las fórmulas de tratamiento como recursos y estrategias de expresión de esas desigualdades.

Luego de esta introducción, el artículo se ha organizado en tres secciones. En la primera de ellas se definen las categorías lingüístico-discursivas de análisis, que operan como reflejo y elemento constructor de las asimetrías referidas. Las dos secciones siguientes, foco central de la exposición, muestran, a través del uso de los tratamientos, el modo de inscripción en los discursos de la época (Calsamiglia y Tusón, 2012) de los grupos humanos ubicados en los polos antagónicos de las jerarquías sociales: por un lado, la población blanca de origen español; por otro, los hablantes de los pueblos originarios americanos y los habitantes de origen africano, referidos genéricamente en los documentos como indios y negros. Previo a las conclusiones, una serie de textos mostrarán, a nivel sintáctico y discursivo, la expresión de la asimetría social.

\section{Categorías lingüístico-discursivas de análisis}

En el abordaje del tema bajo estudio tres cuestiones teóricas resultan fundamentales: a) el concepto de fórmula de tratamiento, uno de los aspectos más controvertidos en la historiografía referida al tema, sobre el que existen controversias, acuerdos y desacuerdos; ${ }^{6}$ b) el campo de aplicación de los tratamientos referenciales, y c) la noción de estilo discursivo cortés.

Consideraremos en primer lugar el concepto de fórmula de tratamiento, cuya delimitación y campo de aplicación subyacen al análisis posterior.

Entendemos por fórmulas de tratamiento al conjunto de formas que poseen los miembros de una comunidad lingüística para dirigirse al destinatario de la emisión o hacer referencia a una tercera persona o a sí mismos en el discurso (Rigatuso, 1992, 2000, 2009). Articulado como fenómeno de la lengua a nivel discursivo y del sistema en español mediante el uso concertado de elementos nominales, pronominales y verbales, es en los usos nominales referenciales -denominados también narrativos o delocutivos- donde se amplía particularmente el campo de aplicación de los tratamientos, al operar, en una triple perspectiva, para la referencia de: a) una tercera persona (Ervin-Tripp, 1972; Murphy, 1988), b) la autorreferencia del productor del discurso y c) como designación de carácter genérico en función narrativa y descriptiva (Álvarez Nazario, 1982) para aludir a hombres, mujeres, niños, como así también para denominar a determinados grupos humanos, unificados por características especiales -sociales, étnicas, políticas, etc.-: gente aparte, gente bien, gringos, cabecitas negras, mazorqueros. En el uso de la forma referencial estos elementos dejan traslucir, así, en forma significativa, evaluaciones del productor del discurso respecto del o los hablantes referidos, y expresan reveladoras actitudes de tipo

6. Una recorrida por los trabajos compilados en los excelentes volúmenes editados por Hummel, Kluge y Vázquez Laslop (2010) y Rebollo Couto y dos Santos Lopes (2011) muestra esta diversidad conceptual. 
social, proyectando su papel al campo de las representaciones sociales (Raiter, 2002; v. Rojas, 2008). En su aspecto léxico, entonces, las fórmulas de tratamiento representan un fenómeno relevante en el conjunto de voces y expresiones que refieren al hombre en distintas etapas históricas de la lengua de una comunidad (Rigatuso, 2008, 2009).

Como hemos anticipado, dado que los discursos con que contamos hasta el presente no testimonian el uso directo por partes de los hablantes ubicados en el polo de menor poder -ni como hablantes ni en su rol interaccional de destinatarios-, nuestro análisis se focalizará en particular en el contraste de las formas que articulan el modo de trato referencial.

En tal sentido, cabe destacar que en español la función básica del tratamiento referencial para la tercera persona es la de individualizar e identificar a la persona aludida, evitando posibles ambigüedades en su referencia que entorpecerían la comunicación (v. Hudson, 1981, p. 128), en consonancia con el principio de 'ser informativos' implícito en las máximas del Principio de Cooperación propuesto por Paul Grice (1975) para los hechos de interacción verbal. La precisión en la información transmitida a través del uso de un tratamiento referencial resulta en consecuencia fundamental para la claridad del mensaje emitido (Rigatuso, 1992).

Desde esta función básica, y al igual que en su uso en modo vocativo aunque con normas propias que rigen su dinámica, en la elección de un tratamiento referencial dos funciones ocuparán lugar central como factores condicionantes, ambas asociadas a la deixis social (Levinson, 1989): su rol como marcadores lingüísticos de relaciones interpersonales en términos de poder/solidaridad y asimetría/simetría vincular (Brown y Gilman, 1960), ${ }^{7}$ y su función como recursos dinamizantes de prácticas de (des)cortesía, al servicio de la gestión interrelacional (Spencer Oatey, 2008), el logro de metas interaccionales y la construcción de imagen e identidad. Las prácticas interlocutivas de la etapa colonial mostrarán en los textos de la época grados diferentes de ponderación de estas funciones, expresados en fenómenos de variación pragmática de los tratamientos referenciales, que reflejan el posicionamiento social y discursivo de los miembros del grupo de mayor poder.

Por último, resulta insoslayable al abordar la problemática de las asimetrías sociales y étnicas en los documentos del Buenos Aires colonial la consideración de la vigencia en los discursos de la época del llamado estilo discursivo cortés (Mc. Intosh, 1986), que, originado en España como modo de comunicación al servicio de una ideología, de una forma de educación y de un estilo de vida particular (Rígano, 2007), transfería metafóricamente en el uso lingüístico la relación de vasallaje a otros vínculos y relaciones, a través de distintos elementos dinamizantes a nivel semántico, pragmático

7. En la elección de un tratamiento referencial en español bonaerense el hablante atiende, por un lado, a su propio vínculo con la persona aludida, y, por otro, al existente entre dicha persona y el destinatario de la emisión, vínculo este último en el que también resulta relevante el poder o la solidaridad existente entre los implicados. 
y discursivo. ${ }^{8}$ En esta retórica discursiva del estilo cortés, atravesada por formalidad, asimetría, y, al mismo tiempo, una marcada expresividad deferencial, los tratamientos ocupaban lugar fundamental, como fenómenos sociopragmáticos nucleares o en coocurrencia y articulación con otros elementos léxicos y mecanismos de expresión de cortesía en la época. Este estilo discursivo atravesó con su impronta distintas tradiciones discursivas (Kabatek, 2005) en el español bonaerense desde la etapa colonial hasta mediados del siglo XIX (v. Rigatuso, 2009).

\section{Los unos: los españoles y sus descendientes}

Desde una perspectiva sociohistórica y discursiva, en relación con las prácticas textuales de la época, los documentos consultados muestran, como uno de sus rasgos preponderantes, un alto nivel de especificación de identidades, circunstancia que se advierte en especial en el uso de los tratamientos referenciales, y se acentúa particularmente en la referencia al grupo dominante. Si bien -tal como señala Cristina Klamnt (1999) en su artículo Estudio de la aposición en documentos coloniales de Tucumán (Argentina)-, esto puede ser consecuencia del tipo de discurso administrativo predominante en las fuentes, a la luz del complejo entramado social referido, marcado por asimetrías y contrastes de status étnico, es muy probable que este hecho se viera reforzado por el deseo de los hablantes de la época de realizar una notable marcación de identidades y de papeles sociales (Rojas, 1992, 1997). No obstante, las formas de especificación y los resultados de las estrategias a nivel de inclusión de los hablantes en el discurso variarán según se trate de personas ubicadas dentro de la escala del poder -los españoles y sus descendientes- o de personas no pertenecientes a dicho sector, los miembros de los grupos étnicos señalados.

En el grupo dominante, la producción de estos discursos aparece asociada a uno de los rasgos más caracterizadores de las actitudes sociales de los conquistadores y pobladores que arribaron a América acompañados de un sentimiento de nobleza (Rosenblat, 1964; Rojas, 1997), y las de sus descendientes: su afición hacia la manifestación y recepción de cortesías y, en ese marco, hacia tratamientos altamente

8. En los documentos de Buenos Aires de la etapa colonial adquiere particular significación la vigencia en distintos discursos del estilo discursivo cortés (Mc. Intosh, 1986) que, originado en el español peninsular a partir de un estilo de vida y como reflejo de una ideología de la clase noble que se distinguía de los otros estamentos sociales a través de sus pautas de comportamiento (Rígano, 2007), toma términos del vocabulario especializado de la corte y los emplea, más allá de su uso en la corte o con personas de la nobleza y la realeza, para expresar cortesía y crear elegancia verbal (Mc. Intosh, 1986, p. 69), transfiriendo metafóricamente, en el uso lingüístico, el vínculo vasallático a otros ámbitos y relaciones (ibid.., Fontanella 1994; Rigatuso, 2004, 2006, 2009). En la etapa de asentamiento de los españoles en suelo americano, en los siglos XVI y XVII, el estilo cortés se encontraba en España ya cristalizado, regulado y codificado en sus elementos lingüísticos y paralingüísticos como forma discursiva de interacción social (Rigatuso 2005, 2006; Rígano, 2007). Otros rasgos caracterizadores del estilo cortés como práctica discursiva son, a nivel del léxico, el empleo de términos tales como merced, honor, favor, servicio, interés, bondad, etc., que definen valores socioculturales predominantes en las relaciones interpersonales de las etapas de conformación del estilo, y una serie de rasgos paralingǘísticos y gestuales que se integran con los elementos lingüísticos en la construcción del discurso cortés (beso en la mano, reverencia, etc.). Sobre la conformación del estilo cortés en España véase la exhaustiva investigación de Rígano (2007). Para un análisis de la funcionalidad social y pragmática de los tratamientos en el discurso de cortesía del español bonaerense de la etapa colonial véase Rigatuso (2009). 
deferentes, que destacan honoríficamente al destinatario o al referente de la emisión, en un interjuego de roles e imágenes que contribuye al refuerzo de su imagen social (Goffman, 1967). Tal como señala Ángel Rosenblat en La base lingüistica del español americano:

Los conquistadores, que se sentían nobles, adaptaron las formas expresivas de la clase aristocrática, en primer lugar en las cortesias y tratamientos, signos de clase o de grado. Al convertirse ellos en capitanes, alcaldes, regidores, etc., tomaron el lenguaje del oficio, y su norma fue el uso caballeresco. Observa José Durand que de capitán a capitán se cambiaban los saludos más exquisitos y se guardaban la mayor cortesía. Andrés de Tapia, uno de los capitanes de mayor confianza de Cortés, al mencionar a sus compañeros no los bajaba de caballeros o gentiles hombres. (...)

América (...) era hipersensible a los tratamientos que se sentian como signo de consideración social, y todos apetecia -era cuestión de honra- el más alto. (Rosenblat, 1964, p. 215 y 218) (el destacado nos pertenece).

Y apunta el prestigioso filólogo más adelante:

ya en la misma hueste conquistadora, y aún más al constituirse la sociedad hispanoamericana, se produjo una nivelación igualadora hacia arriba, una "bidalguización". El hecho de la conquista hizo que todos se sintiesen señores, con derecho a títulos, y adoptasen como modelo superior los usos, y entre ellos los usos lingüísticos, de las capas superiores. (1964, p. 230) (El destacado nos pertenece)

El empleo de estas formas, de carácter identitario y estratégico, les permitía reubicarse en el contexto colonial de la sociedad de la época, en un uso afiliativo (Bravo, 1999) de construcción de imagen, posicionándose con frecuencia, a través del uso lingüístico, en los vértices superiores de la escala social, por encima del estrato al que pertenecían por su origen en la Península. En relación con este aspecto del uso de la lengua, se convertían así en "receptores autorizados” (Levinson, 1990) de esas formas jerárquicas, altamente pautadas desde España a través de políticas lingüísticas reguladoras de su uso (Bañón, 1993; Rigatuso, 2008, 2009), status social e interlocutivo que se proyectaría luego en las prácticas discursivas de sus descendientes en el Río de la Plata. Al mismo tiempo, la elección para la gestión interrelacional de tratamientos que eran "signos de consideración social” (Rosenblat, 1964) por parte de los miembros del grupo dominante coadyuvaba a la marcación de asimetrías con otros grupos humanos componentes de la sociedad a través de los contrastes expresados mediante estrategias lingüísticas diferenciadoras, de las que nos ocuparemos a continuación. Particular interés presenta, en tal sentido, el abordaje de los recursos lingüísticos articulados en la selección de los tratamientos como estrategias discursivas que contribuían a construir, a través de las producciones discursivas de los hablantes, esa nueva identidad social, que se transferiría luego a sus descendientes nacidos en suelo americano en la etapa colonial.

En el marco del referido estilo discursivo cortés, los tratamientos vocativos y referenciales -y, en forma concomitante, las pautas de uso nominal-pronominal-verbal en las que ellos se insertaban a nivel de relación interpersonal y discursivo- se caracterizaban por una marcada deferencia y cortesía. Esta deferencia, cortesía y ceremoniosidad se lograba mediante un conjunto de rasgos que definían la dinámica de los tratamientos de la época, con estrategias constitutivas que implicaban, a nivel léxico y discursivo: la índole del (los) tratamiento(s) nominal(es) núcleo, los elementos con los que dicha(s) 
forma(s) coocurria(n) y los modos de inserción discursiva de las fórmulas de tratamiento resultantes de dichas estrategias de construcción. Así, los distintos documentos de índole institucional y social de la época se definían en tal sentido a partir de:

a) el predominio de tratamientos formales y corteses del tipo de señor-señora, don-doña;

b) el uso de adjetivos de carácter marcadamente deferentes: muy magnifico señor y de carácter honorífico: su señoría ilustrísima, el ilustrísimo y reverendísimo obispo, coocurrentes con la (s) fórmula(s) núcleo.

c) el empleo de posesivos que connotaban pragmáticamente respeto y deferencia: su majestad, su señoría, su merced;

d) el empleo de expresiones frasales corteses, algunas de ellas en aposición: su majestad (que Dios guarde);

e) la elevada frecuencia de uso y la aplicación de títulos de cortesía a voces como individuo(s) y difunto(s), práctica no usual en español bonaerense actual: señores individuos, señor difunto;

f) la complejidad sintáctica de los tratamientos nominales, a partir de la acumulación sintagmática de fórmulas nominales y los elementos en coocurrencia: el Ilustrísimo señor $d^{\text {h }}$ (don) Jhosep. Antonio de Vasurco y Herrera dignisimo obispo que fue de esta Deocesis, y de formas en coordinación del tipo de padre y señor.

A la referida especificación de identidades contribuía igualmente la sintaxis de la época. Nos referimos en particular a construcciones sintácticas del tipo de vecino que fui, obispo que fue -ausentes hoy en español bonaerense-, incluidas en la estructura de fórmulas complejas como las que acabamos de ejemplificar (véase f) que contribuían, a través de un proceso de topicalización, a la ponderación de elementos. Esta construcción corresponde al tipo de estructura que Elizaincín Malcouri y Bertolotti (1997) han definido en sus estudios sobre el español en el Uruguay del siglo XVIIII como complemento adnominal cuyo núcleo se ha dislocado, destacando que constituyen construcciones "modificativas de naturaleza explicativa", que expresan una cualidad del antecedente (1997, p. 52). Se trata, como afirma Alarcos Llorach (1994) de "construcciones enfáticas”' (ibid.; Rigatuso, 2008).

Respecto de la índole de los tratamientos nominales (véase a), señor-a presenta en la época una connotación de marcado tono cortés, en la que perduran rasgos de su significado medieval asociado a dueño y a 'tener poder sobre algo' (Fontanella de Weinberg, 1994). Su presencia frecuente en la

9. Al analizar estructuras del tipo de viuda que fui, soldado que ha sido, acompañando la mención de personas, Elizaincín et. al. señalan que se trata de construcciones "modificativas de naturaleza explicativa", ya que expresan una cualidad del antecedente (1997, p. 52). Postulan, además, al abordar esta cuestión, dos posibilidades de interpretación: a) sustantivo acompañado de otro sustantivo en aposición, al que sigue una estructura relativa, y b) sustantivo modificado por una relativa cuyo atributo se encuentra topicalizado, anteponiéndose aún al nexo (ibid. 53). En su trabajo, que arroja luz sobre esta cuestión, los autores optan -muy acertadamente, a nuestro entender- por la segunda interpretación, aportando sólida argumentación al respecto. 
construcción de los tratamientos referenciales coloniales de índole formal, como forma en aposición que precede la coocurrencia de una o más fórmulas nominales en construcción sintagmática, contribuía a realzar la deferencia y cortesía expresadas.

Por su parte, estructuras referenciales de diversa complejidad de la época incluían también el título social don-doña, cuyo uso adquiriría en América nuevo valor social, con su desplazamiento desde título de privilegio al que se accedía en España mediante pago de un tributo monetario a tratamiento respetuoso para la gestión de vínculos en el dominio social y en ámbitos institucionales (Rosenblat, 1961).

Otras veces, los tratamientos referenciales de carácter formal y cortés incluían el empleo de la fórmula socialmente prestigiosa vecino-a, marcada en la época como expresión de una jerarquía asociada al campo político-institucional. ${ }^{10}$

En cuanto a las subcategorías nominales de tratamiento, además de las fórmulas sociales recién citadas y el Nombre personal, las fórmulas referenciales incluían Términos de tratamiento de indole ocupacional, institucional, administrativa y profesional, que refieren cargos, profesiones y altas dignidades, Titulos de nobleza y Fórmulas correspondientes a grados militares (ej.: $s^{r}[$ señor] Maestre de Campo don Xacinto de Laris Cauallero Der orden de santiago gouern. ${ }^{\circ r}$ [gobernador] y capitan gl [general] desta prouinzia).

La conjunción de estas fórmulas nominales, en las se producía social, pragmática y discursivamente la asociación estratégica entre la función individualizadora y la gestora de cortesía de los tratamientos referenciales, vinculada con la construcción de identidad, se manifestaba también en la autorreferencia del productor del discurso en su inserción textual según prácticas escriturarias de la época, como en el ejemplo que citamos a continuación, correspondiente a la instancia inicial de la venta de un miembro de la población de origen africano, en un Acuerdo del Cabildo:

1. ACUERDOS DE REAL HACIENDA - 1636-1691 (1691) AGN - Sala IX - 13-8-8 Folios 446 y sgtes.

// [Margen: Venta de Vn negro el cap ${ }^{\mathrm{n}} \mathrm{Ju}^{\mathrm{n}}$ de zamudio a Ag. ${ }^{\mathrm{n}}$ de Vretta]

Sea notorio a los Señores que la Presente Vieren que Yo el capitan Don Juan de Zamudio Cauallero del horden de Santiago Vezino morador de esta ciudad de la trinidad Puerto de B, ayres Prou, as del rrio de la plata que otorgo doy en Venta Real desde agora para en todo tiempo. (Rigatuso y Suardíaz, 2008)

Junto a estas estrategias discursivas en el uso de los tratamientos, una categoría de fórmula resultaba particularmente operativa para la expresión de cortesía y asimetría: los denominados Tratamientos honorificos (Lapesa 1970), ubicados en la escala semántica/pragmática de la formalidad en el polo máximo de cortesía, deferencia y ceremoniosidad. Su elección implicaba, en consecuencia, la manifestación del grado máximo de asimetría y deferencia.

10. Sobre el uso del tratamiento referencial vecino-a y su valor como fórmula institucional y marca social en el español de Buenos Aires de la etapa colonial véase Rigatuso, 2008. 
Como categoría de tratamiento, la subcategoría de tratamientos honorificos (Rigatuso, 1992, 2016) estaba integrada por un conjunto de formas para la segunda persona compuestas por vuestra osu + un sustantivo abstracto que destacaba una cualidad del destinatario (majestad, señoría, merced, etc.), en concordancia con verbos en tercera persona singular: su majestad, vuestra (su) señoría, su merced. Desde el punto de vista sociolingüístico y pragmático, funcionaban como fórmulas altamente respetuosas y deferentes que se dispensaban a individuos a los que se reconocía una jerarquía superior, adquiriendo, además, protagonismo peculiar en la manifestación del estilo cortés. En efecto, frecuentes en los sistemas de tratamientos de diferentes lenguas del mundo, estos elementos, vinculados muchas veces a ideologías culturales relacionadas con poder, representan dentro de la perspectiva interaccional, uno de los más claros recursos de focalización honorífica de destinatario o referente (Haverkate, 1994), de particular relevancia en el significado y construcción de las relaciones sociales y dentro de contextos institucionales definidos. ${ }^{11}$ En carácter de tal, en los contextos institucionales de la época, su uso se regía según dignidades y cargos que determinaban la elección de honoríficos específicos, fuertemente ligados a cuestiones de políticas lingüísticas ejercidas por la corona española, que reglamentaban usos protocolares (Bañón, 1993; Rigatuso, 2009). Se empleaban asimismo para la designación honorífica de una tercera persona, en este caso construidas siempre con el posesivo su, modalidad pragmática referencial que nos interesa destacar especialmente en el conjunto de formas delocutivas en contraste bajo estudio.

Las fuentes documentales de la Colonia testimonian una notable profusión de tratamientos honoríficos, que muestra, por un lado, usos estamentarios claramente diferenciados destinados a personas que ocupaban posiciones significativas en la escala jerárquica de la sociedad colonial administrativas y eclesiásticas-, y, por otro, usos no protocolares vigentes en la interacción lingüística cotidiana. En el primer sentido algunas de las formas registradas son: Vuestra (su) majestad (dirigida al rey/reina), Vuestra (su) excelencia (al virrey), Vuestra(su) señoría (al gobernador y capitán general), Vuestra (su) merced (para el alcalde de segundo voto) y Vuestra (su) señoría ilustrísima (destinada a los obispos). También se destinaban a instituciones en su conjunto, tal el caso de su señoría dispensado al Cabildo como institución. Junto a ellos, las fuentes muestran el uso de su merced de hijos a padres, de nueras a suegros, y en algunas relaciones de tipo social. Constatable su empleo en documentos de todo el período que estamos considerando, el testimonio de estos usos honoríficos se hace más frecuente en los documentos del siglo XVIII.

En el caso específico de la dinámica de los tratamientos honoríficos como fórmula para el trato referencial, según los datos del corpus, la ponderación cortés del aludido se expresaba mediante la construcción su(s) + sustantivo abstracto núcleo (su merced, sus mercedes, su señoría, sus señorías, su señoría

11. En relación con la problemática de los tratamientos honoríficos resulta insoslayable el artículo de Rafael Lapesa Personas gramaticales y tratamiento en español (1970), fundacional sobre el tema. Teniendo como punto de surgimiento insoslayable la incorporación de vuestra merced al español y sus definitorias repercusiones históricas (Koch, 2008), y como valioso antecedente este artículo de Lapesa, en la historiografía lingüística el estudio de los honoríficos ha concitado largamente la atención de especialistas en distintas variedades de español, cuya revisión escapa a los límites acotados de este trabajo. 
ilustrísima, su majestad, etc.), que replicaba en el trato para la tercera persona el honorífico núcleo correspondiente para el trato directo, o a través del empleo de adjetivos honoríficos (excelentísimo, ilustre, ilustrísimo-a, dignísimo, magnifico), que acompañaban y precedían complejas construcciones sintagmáticas, iniciadas por el tratamiento de máxima cortesía señor (excelentísimo señor), en coocurrencia sucesiva con tratamientos corteses, sociales e institucionales de la índole de los ya referidos, que especificaban la identidad del aludido (por ejemplo: excelentísimo señor + titulo nobiliario + cargo administrativo/institucional). A nivel discursivo, la dinámica de los honoríficos como estrategia discursiva de ponderación referencial cortés apelaba al uso reiterado de la fórmula en el marco de un mismo discurso, con frecuencia sin necesidad de apelar a la identificación del referente mediante el empleo del nombre de persona o institución, ya que, en su condición de formas marcadoras de status (Ervin-Tripp, 1974), altamente pautadas para su empleo con un hablante determinado en su rol institucional, resultaba inequívoca la identidad del aludido referida por esa forma de trato reverencial. ${ }^{12}$ Así, con el empleo de estos tratamientos de marcado tono cortés se producía discursivamente una identificación honorífica, que reconocía dignidades y resaltaba jerarquías. Citamos a continuación ejemplos del uso de honoríficos en documentos de la época correspondientes a distintos dominios de uso y diversos géneros discursivos, en vínculos interpersonales entre desconocidos y conocidos, dentro de la diacronía considerada. Como veremos, en estos ejemplos la dinámica de los honoríficos, inmersa en el entretejido textual cortés predominante, aparece en coocurrencia con otras fórmulas de tratamiento, constituidas según las estrategias sintácticas, léxicas y discursivas señaladas más arriba, y coadyuvantes, en tal sentido, a la expresión de deferencia y formalidad.

\section{Muy magnifico señor:}

Por dos vías tengo escrito a v. m. muy largo y así seré breve en|ta, (...) pues esa tierra es tan trabajosa como se entiende, que pudiendo dejar la deje, y si de presente no pudiere, apercíbase para cuando alguna gente de ese pueblo viniere al Río de la Plata al gobierno del señor licenciado Juan de Torres de Vera, porque casó su merced con la hija del adelantado Juan Ortiz de Zárate, gobernador de aquel reino, y sucede el señor licenciado en él. (...) Porque el señor licenciado me hace tanta merced y amistad, que no desea otra cosa sino ver cosa mías para les honrar y aprovechar. (Carta de Baltasar Sánchez a su hermano Gaspar Sánchez, 22-1-1578, en Otte, 1982, p. 561)

3. BANDOS DEL LIBRO I - MOLIENDA DE FANEGAS DE TRIGO (1748) - AGN Sala IX - 8-10-1 Folio 214 y sgtes.

En la Ciudad de la Santissima Trinidad Puerto de Santa Maria de Buenos Ayres, a Veinte, y dos de octubre de mill setecientos quarenta, y ocho a. en Acuerdo que Celebro oy dia de la fecha el Ilustre Cavildo Justicia, y rexim. ${ }^{\text {to }}$ entre otras cosas que se trataron sobre el bien pro, y Vtilidad de esta republica, y sus havitadores. Haviendose propuesto por el Señor Alcalde de primer Voto Don Fran $^{c o}$ Rodriguez de Vida. Que por quanto â los dueños de Tahonas se les ha tolerado Costumbre, el haver pagado mas de quatro, haviendo sessado las Causas que ocurrian de escases de Cavallos los Meses passados,(...) Se suplique al S.r. [Señor] Gov. or [Gobernador] y Capitan Grâl [General]. se sirva su señoria, mandar se rompa Vando, ordenando que dichos Tahoneros, no cobren, ni recivan mas estipendio que los expressados (...). (Rigatuso y Suardíaz, 2008)

12. Un claro ejemplo al respecto lo constituye el uso de los tratamientos honoríficos de carácter referencial en diversas instancias de la transcripción de juicios de la época. 
4. ACUERDOS DE REAL HACIENDA - 1636-1691 (1653) - AGN - Sala IX - 13-8-8 Folios 150 y sgtes.

(...) asimismo la cantidad, con que fue socorrida desta real caxa La compañia de ynfanteria, que bino de socorro a este puerto de la prouincia de tucuman por orden del exselentisimo señor conde de saluatierra virrey destos Reynos, y señor Doctor don francisco de Nestares Marin Presidente $Y$ visitador de la real audiencia de la plata $=$ Y tambien para que lleue La cantidad de plata que ay en esta $\mathrm{R}^{1}$ caxa prohiuido su uso por prematica de su magestad, con que no ay plata en ella corriente, para poderse yr socorriendo, a los soldados, como se â ydo haziendo de La que â auido hasta agora por prestamo, en conformidad de orden del señor Marques de manzera virrey que fue destos Reynos. (Rigatuso y Suardíaz, 2008)

En el papel estratégico de las fórmulas de tratamiento al servicio de la autopresentación positiva de Nosotros frente a Ellos (Van Dijk, 2003), en el discurso de las fuentes coloniales que estamos considerando, los tratamientos honoríficos representaban, dentro del grupo de los españoles y sus descendientes, el recurso más claro de expresión de cortesía deferente entre pares y de asimetría social vinculada al papel institucional de los hablantes, al mismo tiempo que reflejaban, por el contraste con los recursos lingüísticos referenciales para la alusión de los otros grupos humanos, las fuertes diferencias de poder que pautaban la pluralidad étnica existente en la sociedad colonial: su funcionalidad sociocomunicativa se dinamizaba entonces entre la expresión de cortesía y de poder.

\section{Los otros: indios, mestizos, negros y mulatos}

En el otro extremo de la escala social, los miembros de los pueblos originarios americanos, los de comunidades africanas y los habitantes nacidos como resultado de la unión entre personas de diferentes grupos étnicos aparecen inscriptos en el discurso de la época con formas referenciales marcadamente antagónicas, en su índole, conformación estructural y connotación, a las dispensadas al grupo de los españoles y sus descendientes. A la complejidad estructural de las fórmulas destinadas a los hablantes del polo de mayor poder se opondrá una mayor simpleza sintáctica, a la connotación marcadamente deferente y cortés de las formas constitutivas se opondrá la selección de voces que rescatan rasgos étnicos, a la inserción de los tratamientos en discursos plagados de voces de connotación positiva, que exaltan virtudes o actitudes de los hablantes, articuladas en el entretejido textual del estilo discursivo cortés, se opondrá la presencia de piezas léxicas y expresiones asociadas a la referencia de las personas, de carga negativa, que patentizan su condición en la sociedad de la época colonial.

El elemento nuclear de estos referenciales lo constituyen las voces que designan en la época al hombre según su pertenencia étnica o rasgo étnico -indios, negros, mulatos, etc.-. Según los datos del corpus, estas formas se integraban en: fórmulas referenciales genéricas -un negro, una negra-, formas de referencia colectiva -los negros- y formas de designación individualizadora -el negro Tomás-, en las prácticas discursivas coloniales todos ellas al servicio y como expresión de las marcadas asimetrías de la época. ${ }^{13}$

13. Algunas de estas voces se corresponden con los llamados antropónimos y etnónimos y al conocimiento de ellos aportan desde su impronta sociocultural. 
Nos referiremos a continuación a los usos referenciales registrados hasta el momento en nuestros documentos para los miembros de estos grupos humanos. Para ello, seguiremos la clasificación de elementos y componentes propuesta por Germán de Granda en su artículo Onomástica y Procedencia Africana de esclavos negros en las minas del sur de la gobernación de Popayán, siglo XVIII), a partir de los usos consignados para la referencia de los pobladores de origen africano en matrículas de esclavos pertenecientes a minas de la zona suroccidental de la actual Colombia (de Granda, 1988, p. 49), que comprende:

a) Componente racial: negro, mulato, pardo, etc. (...).

b) Circunstancia de nacimiento: criollo (nacido en América), bozal (nacido en África).

c) Nombre cristiano.

d) Gentilicio referente a la procedencia africana. Nombre de familia castellano, otorgado generalmente por los propietarios a sus esclavos a través del padrinazgo de bautismo.

e) Adjetivos que aluden a cualidades o defectos físicos o morales. ${ }^{14}$

Estas marcas de clasificación se combinaban en una variada gama de estructuras que daban lugar a distintas formas referenciales. Asimismo, según señala de Granda, la clasificación propuesta, de carácter dinámico, debería ser ampliada con el uso de nuevos elementos registrados en otras fuentes documentales, tal el caso, por ejemplo, de las denominaciones de oficios (de Granda, 1988, p. 52), ${ }^{15}$ rasgo que relevamos en nuestros documentos del Buenos Aires colonial.

Similares criterios de clasificación empleamos en el análisis de los referenciales que designan a miembros de las comunidades indígenas.

Cabe destacar que, en el conjunto de elementos recién referidos, el primero de ellos -el componente racial- constituye en sí mismo objeto interesante de análisis desde la perspectiva léxica, en relación con las formas de designación general de los distintos grupos étnicos, no solo por su vigencia en el repertorio lingüístico de la época sino también por el valor de dichas voces asociadas a la problemática de las representaciones sociales, y como emergente lingüístico de prejuicios y desigualdad sociales.

En las fuentes documentales consultadas aparece un uso predominante de referenciales integrados por una voz que remite al componente étnico (negro-a, mulato-a, indio-a) precedido o seguido del nombre de pila, sin presencia del apellido (Juan indio. la india María Salomé). Siguiendo tradiciones escriturarias de la época, con frecuencia, la incorporación del nombre en el discurso aparece precedido por el ítem llamado-a o, nominado-a (un mulato llamado Marcos). Los siguientes textos muestran ejemplos de estos referenciales en dos tipos discursivos de la época: acuerdo del Cabildo y testamento.

14. Para un análisis de los tratamientos referenciales dispensados a la población de origen africano en documentación colonial administrativa de la comarca de Patagones siguiendo el esquema de de Granda, véase Araque (2002).

15. Respecto de la operatividad de estas formas de referencia señala de Granda: "La flexibilidad de aplicación de semejantes normas da lugar a un 'continuum' designativo que oscila entre los dos polos de la mínima y la máxima individuación. Entre el mandinga o el ocara sin más designación y el Juan Monte Peralta” (de Granda, 1988, p. 50). 
5. CABILDO DEL 3 DE SEPTIEMBRE DE 1607 - AGN - Sala IX - 27-6-5 - Acuerdos del Extinguido Cabildo de Buenos Aires - Tomo I 1605-1608 - Folios 206v y 207

pregones y vos de la Romana y Correduria desta ciudad en buenos ayres. a once dias del mes de sept $^{\mathrm{e}}$ de mill e seiscientos y siete $\mathrm{a}^{\mathrm{s}}$. en cumplim..$^{\text {to }}$ : de lo que su s. ${ }^{\mathrm{a}}$ [señoría] del $\mathrm{Cau}^{\mathrm{o}}$ [Cabildo] probeyo. cerca de la Romana y Correduria desta çiudad en que se pregonasen por tiempo de vn año. fuy à la placa desta çiudad y se pregono la Romana con bos alta de $J u^{n}$ indio.y y dixo(...) $\mathrm{y}$ dho [dicho] este primer de $\mathrm{q}$ [que] doy fee Martin de Marechaga escriu ${ }^{\circ}$ [escribano] $\mathrm{p}^{\text {co }}$ [público] y de $\mathrm{Cau}^{\circ}$ [Cabildo] (Rigatuso y Suardíaz, 2008).

6.TESTAMENTO DE DOÑA ANA DE ESCOBAR (1721) - AGN - Sala IX - Registro No 3 (Bervano - 1720-1722) Folios 375 y sgtes.

(...) no se me dio en dote Cassa ninguna ni el dho [dich] mi marido trajo ningunos bienes; $\mathrm{Y}$ despues que murieron los dhos [dichos] mis Padres en el Repartimiento que se hizo entre sus herederos me toco de Legitima Paterna y Materna Vna negrita de quatro a Cinco años nombrada Maria la qual biue oi; assi mismo una Caxa del Bracil el sitio de la Cassa en que al press.te biuo (...)Itt declaro y es mi Voluntad que la dha [dicha] negra maria por auerla criado gose desde oi en adelante de Liuertad y [...] Como persona Libre y no Sugeta a esclauitud ni servidumbre alguna; Cuia Liuertad hago y otorgo en fauor de la Sussodha por los muchos y buenos beneficios q me a hecho y por que espero de su buen obrar lo egecutora en adelante y esta Clausula le sirua de Carta de Liuertad en forma. (Rigatuso y Suardíaz, 2008)

Nótese cómo la construcción componente étnico + nombre referido a una pobladora de origen africano, sin apelación al apellido, aparece también en el fragmento correspondiente al testamento, en el otorgamiento de la libertad -acto legal de manumisión por testamento en el Derecho romano.

En coincidencia con lo apuntado por Germán de Granda, otras formas registradas en nuestras fuentes incluyen en la construcción referencial, junto al componente étnico y el nombre, formas en aposición o complementos que aluden a la procedencia africana o americana, a la circunstancia de nacimiento, a algún rasgo físico, dato de edad o a la tarea desarrollada por la persona: Joseph Negro, que hase oficio de pregonero; Vn negro esclauo Casta angola nonbrado Melchor; una negra llamada Dominga criolla; Luis Romero Indio Natural del Paraguay; el Indio Ciego Juan de Acosta. Ilustran estos usos los siguientes textos:

\section{BANDOS DEL LIBRO I - PROHIBICIÓN DE VENTA DE ARMAS Y BEBIDAS ALCOHÓLICAS A INDIOS (1742)}

En B.s Ay.s dho [dicho] dia mes y año Yo el ess.no [escribano] de Gov. [gobierno] no sali de la fortalesa de esta Ciu,d [ciudad] acompañado de los Sargentos y Cauos [Cabos] de esquadra de este Precidio y a son de Cajas de Grrâ. [Guerra] y por Vos de Joseph Negro, que hase oficio de pregonero hize publicar el Vando destas foxas. (Rigatuso y Suardíaz, 2008)

\section{BANDOS DEL LIBRO I - EXPULSIÓN DE VAGOS DE LA CIUDAD CON EL FIN DE DISMINUIR ROBOS (1746)}

En Bus Ays dho dia mes y año Yo el essno

// de Gouno Sali de la fortaleza de este Castillo acompañado de los Sargtos y Cauos de esquadra de este Presidio y a Son de Caja de Guerra y por Voz de Joseph de Peralta Indio que haze oficio de Pregonero hize publicar el Vando antesedente en los Parajes acostumbrados de que doi fee. (Rigatuso y Suardíaz, 2008) 
9. ACUERDOS DE REAL HACIENDA - 1636-1691 (1691) AGN - Sala IX - 13-8-8 Folios 446 y sgtes.

Sea notorio a los Señores que la Presente Vieren que Yo el capitan Don Juan de Zamudio Cauallero del horden de Santiago Vezino morador de esta ciudad de la trinidad Puerto de B,s ayres Prou,as del rrio de la plata que otorgo doy en Venta Real desde agora para en todo tiempo â Agustin de Vreta residente en este Puerto para el suso dho [susodicho] Sus herederos ô quien Su caussa $Y$ poder tubiere o susediere en el drô de esta escritura en qualquier manera que Sea es a saber Vn negro esclauo Casta angola nonbrado melchor de hedad de Veinte $\mathrm{Y}$ tres años que enbarque este Presente Año en la ciudad de cadiz Y traxe a este Puerto de Buenos ayres en los nauios de Rexistro que estan surtos a Su Vista. (Rigatuso y Suardíaz, 2008)

10. TESTAMENTO DE JUAN ANTONIO DE ARREGUI (1686) - AGN - Escribanías Antiguas - Protocolos 1584-1690 - Sala IX - 48-1-1- Folios 627 y sgtes.

declaro qe Cassê a mi hija Anna con el capitan D. Ju,n de Armaza Y le mandê en dotte cinco mil pessos en los generos $Y$ cossas qe Contiene Una memoria que para el efeto se hico $\mathrm{Y}$ abaluado por el contador Dn Po de Aluarado Y el capitan Jun Matheo de Arregui difunto que [...] para en poder $\mathrm{Y}$ registro del secret.o Thomas Gapasso por auerse pressentado quando se embargaron los Vienes del dho capitan D. Jun de Armaza mi hierno. quando se fue a Lima a presentarse y qe en la dha memoria estan Una cassa en dos mil pessos qe le prometi edificar y una negra llamada Dominga criolla en quinientos pessos. despues se reconvino Y pidio le apartasse sobre lo qe tenia rezeuido por la dha memoria abaluada Cumplimiento a los dhos cinco mil pesos de la promesa en plata. (Rigatuso y Suardíaz, 2008)

\section{CAUSA CRIMINAL SEGUIDA CONTRA EL INDIO TOMAS VILLANUEBA} POR MATAR A OTRO INDIO (1772) - AGN - Sala IX - División Colonia - Sección Gobierno - Tribunales - Legajo 293-39-9-8

(...) En Buenos Ayres a veinte y ocho de dho mes y año en prosecuzion de esta sumaria hizo su Merced compadecer ante si a Luis Romero Indio Natural del Paraguay y para q.e declare le rrecivi Juram.to q.e lo hizo por Dios nuestro señor (....) por qe constando del processo, qe este homicidio fue causado, con un golpe de ladrillo, es claro, qe avn caso negado, q.e el indio Villanueba fuesse el causante, no debe ser condenado a pena de muerte por haver en el faltado el animo de matar precissamente necessario para imponer esta pena, y mas si se considera, que teniendo otro instrumento mas poderoso en vn cuchillo para causar la muerte como lo exponen el Indio Ciego Juan de Acosta, y Maria Salome, no quiso usar de el, sino qe se Valio de otro menos fuerte, para inferir la herida. (Rigatuso y Suardíaz, 2008)

Los ejemplos recién citados permiten advertir algunas construcciones referenciales que muestran para los miembros de los grupos étnicos bajo estudio el empleo del apellido, en particular aplicado a miembros de las comunidades indígenas y a mulatos. Todos ellos incluyen no obstante la voz que remite al grupo étnico. Es decir, según muestran los textos consultados, aunque se les hubiera atribuido nombre y apellido españoles, y se recurriera a ellos para su mención, en la amplia mayoría de los casos la marca étnica parece ineludible en la construcción del modo referencial. En nuestras fuentes, este uso se registra en general en documentación oficial de tipo legal y padrones (indio Villanueva; Luis Romero, Indio Natural del Paraguay).

Resta consignar en el grupo de referenciales empleados para los hablantes de origen africano, la voz negrito-a, que, a través del uso del diminutivo, en su aplicación a niños, parece connotar cierto 
grado de afectividad. Los ejemplos con que contamos corresponden a pobladores de ese origen que han sido criados desde pequeños en el seno de una familia, en documentación del siglo XVIII. Este es el caso del testamento que citamos más arriba producido por una mujer al referirse genéricamente a una negrita, a quien le otorga luego la libertad, y la carta familiar que citamos a continuación que consigna el referencial el negrito en una carta entre hermanos:

12. CARTA DE FRANCISCO ANTONIO DE BASAVILBASO A SU HERMANO MANUEL DE BASAVILBASO (1764) - Folio 470 - Correspondencia perteneciente a la familia Basavilbaso (1762-1779) AGN - Sala IX - Sucesiones 4310

// Herm ${ }^{\circ}[$ Hermano]

Mandame p. ${ }^{\mathrm{r}}$ [por] tu vida esta noche con Estanilao vnos . $^{\mathrm{s}}$ [reales] pues me hallo sin din. ${ }^{\circ}$ [dinero] alg. ${ }^{\circ}$ [alguno] p. ${ }^{\mathrm{a}}$ [para] el gasto; s. $\mathrm{P}^{\mathrm{r}}$ la manana mandare al negrito por ellos; y perdona mis molestias

$=\mathrm{Tu}$ afect. ${ }^{\mathrm{mo}}$ herm. ${ }^{\circ}[$ hermano]

Fran. ${ }^{\mathrm{co}}$

Enero 2 de 64 - Remiti cuatro $p .{ }^{s}$ [rúbrica] [en el documento, con letra diferente] (Rigatuso y Suardíaz, 2008) $)^{16}$

Por su parte, a nivel de producción textual, en las modalidades de inclusión en los discursos de la época, las voces referidas a los grupos étnicos reflejaban -en sus distintas formas de expresión y aplicación como tratamientos referenciales- el lugar y la valoración de sus miembros en la sociedad colonial. Así, además de la minimización del carácter humano que parece desprenderse en forma implícita de la sintaxis en los testamentos, a través del lugar que ocupaban en la enumeración de objetos legados que hemos visto en fragmentos citados más arriba -consecuencia directa de su condición legal de ser esclavos-, los documentos aportan datos en igual sentido a través de discursos que aluden al tráfico de pobladores de origen africano, como el que citamos a continuación:

13. ACUERDOS DEL EXTINGUIDO CABILDO DE BUENOS AIRES - TOMO VIII (1741) REAL CEDULA DE 10 DE SEPTIEMBRE DE 1741, QUE CONCEDE PERMISO A TOMÁS NAVARRO PARA CONDUCIR A BUENOS AIRES DOS BARCOS NEGREROS Y RETORNAR CON FRUTOS DEL PAIS - AGN - Sala IX - 277-8 Folio 173v y sgtes.

Por quanto Don Thomas Nauarro Considerando la escases de Negros que hay en B.s Ayres y otras Provincias inmediatas a solicitado poner en la Costa de Guinea dos Nauios de a tresientas toneladas cada Vno para Cargar de negros Con bandera y tripulacion neutral a ezepz.on de los Mrêss.

// que han de ser españoles y afianzaran en Cadiz no llebar gen.os algunos bolbiendo â el Puerto de esta Ciudad Con Certificaz.on de haver echo el fondeo de los Referidos Nauios en Buenos Ayres y traiendo solamente el caudal que produjeren los Negros.

(...) Que despues de abastesida la Prov,a de B.s Ayres pueda conducir librem.te los Negros que

16. Según afirma Frida Weber, el posterior uso afectuoso de negra en la lengua de Buenos Aires: "Se suele explicar como herencia colonial, bien por el modo en que el amo se dirigía a la esclava predilecta, o bien como imitación del lenguaje ricamente afectivo de los negros"(Weber, 194, p. 117; v. Rigatuso, 2012). 
le Sobraren al reyno del Peru y Chile y de la Comformidad que lo hasia el Asiento Ingles = Que ha de poder haser la Corambre que nesesite para cargar sus Nauios en la Ciudad de S.n Phelipe de Montebideo y B.s Ay.es francam.te y sin interbenz.on de sus Cauildos ni Gov,or en la misma forma que lo ha hecho el Vltimo Rex.o = Que â estos Nauios se permita // traer a el Puerto de Cadiz el producto de sus Negros en plata Cueros u otros frutos de aquel Paiz Con Rexistro del Gov.or y Ofiz.s R.s sin pagar mas drôs. que los que pago el Vltimo Rexistro que Vino de B.os A. (Rigatuso y Suardíaz, 2008)

Otra expresión discursiva en tal sentido la constituye la presencia de voces asociadas a los miembros de estos grupos connotadas negativamente. Así, en uno de los documentos de nuestro corpus se ofrece en venta a un hablante negro "con todos sus vicios y defectos", y en la transcripción de un juicio que lleva por carátula "Causa criminal seguida contra el indio Tomas Villanueba por matar a otro indio" se refiere: "Toda la sumaria esta reducida â las declarasiones de algunos Indios qe por su propria natural estolides generalmente hablando son mendaces, faciles, volubles, ê inconstantes en sus dichos" (1772). (Rigatuso y Suardíaz, 2008; véase infra)

Por último, las fuentes coloniales consultadas dan cuenta, entre las formas de alusión a los pobladores africanos, del empleo de la voz esclavo-a, que, al operar como alternante léxico de negro-a, reemplazándola en algunas instancias de los discursos, pondera, en el desplazamiento de la voz que evoca el grupo étnico, la situación jurídica de pérdida del estado de libertad.

A nivel de las selecciones léxicas, y en relación con las voces alternantes o asociadas en el discurso, en el mismo sentido de reflejo y expresión de asimetrías sociales parece operar el uso de la voz cría como designación para hijos y niños de esclavos miembros de la población negra, en contraste con la voz hijo-a, niño-a para miembros del grupo de los españoles y sus descendientes. ${ }^{17}$ Veamos un ejemplo extraído de una carta y recibo de dote:

14. CARTA Y RECIBO DE DOTE DEL CONTADOR AGUSTÍN DE LABAYEN EN FAVOR DE DOÑA JUANA DE TAPIA RANGEL - AGN - Escribanías Antiguas Protocolos 1584-1690 - Salas IX - 48-1-1-18-12 - 1644 Folios 716 y sgtes.

y para que tenga Efecto. El dho casamiento. y poder sustentar. sus cargos. y obligaciones. me a offresido. Y prometido El dho. general Juan de tapia. de Vargas en dote con La dha su hija catorce mill pesos. corrientes. de a ocho iapresiados. a los. predios. que ban declarados. que son los. Siguientes (...)

dos negros. nombrados. Pedro y Ynacio. Y una negra muger del dho Ynacio. y una cria nombrada guiomar apresados. en mill y trecientos. y cinquenta pesos. (Rigatuso y Suardíaz, 2008)

Esta asimetría social expresada a través de las diferencias en las piezas léxicas elegidas para el uso referencial parece estar en relación con el empleo de las voces hembra y macho registrado por Álvarez Nazario (1982) en documentos coloniales del español de Puerto Rico, como referencia al sexo de esclavos indios y africanos:

17. Los diccionarios de la época consultados no ofrecen referencia al uso de cría como forma de designación para hijos o niños de seres humanos. 
Los términos macho y hembra, aplicados a personas, se suelen documentar en vez de las formas equivalentes respectivas de varón y mujer (pero también esta última) en referencia al sexo de esclavos indios y africanos (...) 5 esclavos, 3 machos y dos hembras. (1982, p. 193) (Destacado en el original)

\section{Algunos ejemplos de la expresión discursiva del contraste de jerarquías étnicas en el orden social}

Como ejemplo de contrastes y diferencias de jerarquías en el orden social manifestadas por las fórmulas de tratamiento referenciales en los textos, citamos a continuación una serie de fragmentos discursivos correspondientes a un testamento, a una carta y recibo de dote y a una causa judicial. Previamente, presentamos los esquemas referenciales correspondientes:

\begin{tabular}{|c|c|}
\hline $\begin{array}{l}\text { Formas de referencia para españoles } \\
\qquad y \text { descendientes }\end{array}$ & $\begin{array}{l}\text { Formas de referencia para población de } \\
\text { origen africano y de pueblos aborígenes }\end{array}$ \\
\hline 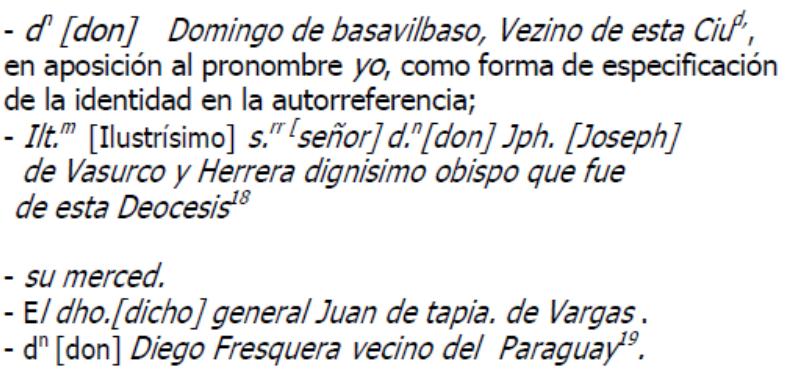 & $\begin{array}{l}\text { - dos negros. nombrados. Pedro y Ynacio. Y una } \\
\text { negra muger del dho Ynacio. } \\
\text { - indio Tomas Villanueva. } \\
\text { - María Salomé Flores India } \\
\text { tape. } \\
\text { - la nominada Maria } \\
\text { salome. } \\
\text { - Antonio Indio. }\end{array}$ \\
\hline
\end{tabular}

\section{TESTAMENTO DE JOSEPH ANTONIO BASURCO, OBISPO DE BUENOS AIRES Y OTROS DOCUMENTOS QUE SE RELACIONAN CON SU FALLECIMIENTO (1761) - AGN - Sala VII - Biblioteca Nacional - Legajo 290 - Documento 4459. $/ /+$}

En el nombre de Dios todopoderoso y con su divina Grazia amen:

Sea notorio a los que la presente Carta de Testam. ${ }^{\text {to }}$ ultima y postrimera boluntad vieren et oyeren, como yo $d^{n}$ [don] Domingo de basavilbaso, Vezino de esta Ciu. ${ }^{d}$ [Ciudad] digo que por quanto el Ilt. ${ }^{m}$ [Ilustrísimo] s. ${ }^{r}$ [señor] d. ${ }^{n}$ [don] Jph. [Joseph] Antonio de Vasurco y Herrera dignisimo obispo que fue de esta Deocesis s, me confirio su Poder para que despues de su fallecimiento hiciese su Testam, ${ }^{\text {to }}$ ârreglado a los Comunicados que me tenia echos, y a las Ins trucciones que p. ${ }^{a}$ el mismo fin me entrego. (Rigatuso y Suardíaz, 2008)

16. CARTA Y RECIBO DE DOTE DEL CONTADOR AGUSTÍN DE LABAYEN EN FAVOR DE DOÑA JUANA DE TAPIA RANGEL - AGN - Escribanías Antiguas Protocolos 1584-1690 - Salas IX - 48-1-1-18-12 - 1644 Folios 716 y sgtes.

(...) me a offresido. Y prometido El dho. [dicho] general Juan de tapia. de Vargas en dote con La dha su hija catorce mill pesos corrientes. de a ocho rreales = en rreales. plata labrada. $y$ otros. bienes muebles. y rrayses. que me quiere entregar. luego de presente apresiados. a los. predios. que ban declarados. que son los. siguientes (...). 
yten, dos negros. nombrados. Pedro y Ynacio. Y una negra muger del dho [dicho] Ynacio.(Rigatuso y Suardíaz, 2008)

17. CAUSA CRIMINAL SEGUIDA CONTRA EL INDIOTOMAS VILLANUEBA POR MATAR A OTRO INDIO (1772) - AGN - Sala IX - División Colonia -Sección Gobierno Tribunales - Legajo 293-39-9-8.

(...) Inmediatamente hizo su Merced compadecer ante si a Maria salomé Flores India tape que dijo ser del Pueblo de Corpus, y para que declare respecto de no estar mui diestra en el ydioma castellano llamo su merced por interprete à $d^{n}$ [don] Diego Fresquera vecino del Paraguay, y para que este haga el oficio de tal le rrecivio Juramento que lo hizo por Dios nuestro señor y una senal de Cruz según derecho

// por el cual prometio de cumplir vien y fielmente con el tal cargo a su lean saber y entender; y por medio de dho interprete se le recivio juramento a la nominada Maria salome que higualmente lo hizo por Dios nuestro señor, y una señal de Cruz seg. ${ }^{n}$ derecho, y encargada, y explicada su gravedad prometio decir la verdad de lo que supiere en lo que se le preguntare y siendole diga lo que sabe acerca de la muerte causada a Antonio Indio quien la ejecutó como, y porque causa dijo por medio de dicho interprete que el Lunes veinte del corriente a la tarde entraron en el quarto donde vive la que declara Antonio Indio (q. ${ }^{e}$ tambien vivia en el) con otro Indio tambien tape su paysano llamado Thomas. (Rigatuso y Suardíaz, 2008)

Por último, la presencia, en los documentos coloniales, de construcciones sintácticas integradas por las formas así como y aunque, manifiesta gramaticalmente, a través de la agrupación de los elementos léxicos que refieren a las identidades étnicas -reforzada, en el segundo texto que citamos a continuación, con el valor concesivo de aunque-, las distancias y diferencias sociales de la época. ${ }^{18}$ Los Bandos del Cabildo ofrecen a través de su discurso institucional testimonios de esta expresión sintáctico-discursiva de las relaciones de poder y asimetrías sociales existentes entonces (véase Rigatuso, 2008):

18. BANDOS DEL LIBRO I - EXPULSIÓN DE VAGOS DE LA CIUDAD CON EL FIN DE DISMINUIR ROBOS (1746) - AGN - Sala IX - 8-10-1 Folios 96 y sgtes.

/ y Mando a todos los Bagamundos assi españoles como Indios, Negros y Mulatos que hubiere en esta ciud y su Juridicion que no tengan oficios ô esten Conchauados que dentro de Ocho dias Salgan de ella pena a los que no lo hubieren de seis años de destierro al Presidio y Plaza de San Phelipe de Montevideo â trauajar, en el en las Obras de S M: A rrazion y sin sueldo. (Rigatuso y Suardíaz, 2008)

19. BANDOS DEL LIBRO I - PROHIBICIÓN A COMERCIANTES DE COMPRAR O GUARDAR OBJETOS PERTENECIENTES A INDIOS, NEGROS O ESPAÑOLES (1747) - AGN - Sala IX - 8-10-1 Folios 134 y sgtes.

por esta razon Se cometen diferentes Hurtos, y hallando los que los hazen quien les compren las Cosas Hurtadas o que se las ôculten los Continuan como se experimenta y si no hallaran compradores ni ocultadores no Serian tan Continuos dhos hurtos $Y$ para que esto tenga remedio y se cuide Ordeno y Mando â todos los mercaderes pulperos y a todas las demas personas. Vezinos estantes y hauitantes en esta Ciudad de qualquier Calidad y Condizion que sean; que

18. Los casos reseñados dejan planteada una línea muy interesante de profundización respecto del estudio de los discursos coloniales a la luz de la propuesta de análisis ideológico del discurso de Teun van Dijk (2003). 
desde oy en adelante Ninguno compre. cossa alguna a Indio, Negro, Mulato, ni otra cu alquier persona forastera, ô sospechoza aunque sea español Cossa alguna. (Rigatuso y Suardíaz, 2008) ${ }^{19}$

Nótese, en el primer ejemplo citado, la división social reflejada en la agrupación de las designaciones de referencia étnica que se corresponde, en el segundo ejemplo, con el mayor grado de confiabilidad atribuido a los españoles a través de la expresión "aunque sea español”. ${ }^{20}$

\section{Conclusiones}

En el marco de tradiciones textuales que tienen como una de sus características la vigencia del llamado estilo cortés (Mc. Intosh, 1986), el sistema de tratamientos referenciales registrado en nuestro análisis para el español de Buenos Aires de la etapa colonial ha mostrado un alto nivel de especificación de identidades institucionales, sociales y étnicas, circunstancia que se verifica a través de la estructura gramatical de los tratamientos nominales, de la selección léxica implícita en su conformación así como en los modos de su inserción en los distintos discursos analizados, producidos por el grupo de mayor poder. Estas posibilidades de selección operan entre polos que establecen una focalización honorífica de los hablantes (Haverkate, 1994) a través de formas altamente deferentes y corteses, que apelan a la acumulación sintagmática de términos de respeto, sociales o ponderativos de cargos y jerarquías, y/o a la elección de un tratamiento honorífico, y usos que, por el contrario, a través de fórmulas antagónicas a aquellas, ubican a los hablantes en estadios inferiores de la composición social. Se trata, en tal sentido, de una conjunción de estrategias contrapuestas convergentes en un mismo fin: la ponderación de sí mismos por parte de los españoles y sus descendientes a través de una focalización honorífica y cortés, y, al mismo tiempo, la construcción discursiva opuesta, por minusvalorización, a través del juego interaccional referencial, de las identidades de los otros grupos humanos, compuestos por indios, mestizos, pobladores de origen africano y mulatos, en cuya alusión parecen operar -junto a la función básica de identificación del aludido provista por el tratamiento referencial- marcas discursivas de exclusión.

19. En relación con el lugar social y jurídico que ocupaban los miembros de la población indígena en el Buenos Aires colonial véase la siguiente afirmación extraída de la transcripción de la causa criminal seguida a un indio a causa del asesinato de otro indio ya citada, en la que se argumenta respecto de la validez jurídica de las declaraciones de los miembros de la comunidad indígena: "Toda la sumaria esta reducida â las declarasiones de algunos Indios qe por su propria natural estolides generalmente hablando son mendaces, faciles, volubles, ê inconstantes en sus dichos según el comun decir de vros Regnicolas $y$ por esso el Concilio Limense Tercero, probibe el q sean llamados â jurar, si no es en causas gravissimas, y q aun en estas no hazen fee alguna; por $\mathrm{q}^{\mathrm{e}}$ ellos en semejantes casos, no hazen mas $\mathrm{q}^{\mathrm{e}}$ declarar segun les parece mas conforme a la voluntad de los Jueces por quienes son preguntados, sin hazerze cargo de la gravedad del Juramento, cuya Religion quebrantan, de modo $\mathrm{q}^{\mathrm{e}}$ en sentir de Nuestro Politico Lobizzano libro $2^{\circ}$ al Cap 28 hablando de la cos// tumbre y estilo de Lima según vna ordenanza de aquel Virrey, recibida otras Prov.' el numero de seis Indios Juramentados no se merecen mas fee, q la de un solo testigo; y en sentir del Fiscal según otros Regnicolas ni aun el numero de dies inducen el mejor testimonio de la Verdad. Con qe no llegando en la sumaria los tgos producidos al numero de seis estamos en el caso, de q no haya ni avn semiplena probanza de haver sido el Reo quien perpetro el homicidio; $\mathrm{y}$ por consiguiente, $\mathrm{q}^{\mathrm{e}}$ no es acreedor â la pena, $\mathrm{q}^{\mathrm{e}}$ se le pretende imponer por la asusasion Fiscal" (Archivo General de la Nación, Causa criminal seguida contra el Indio Tomas Villanueba por matar a otro indio, 1772; en Rigatuso y Suardíaz, 2008).

20. Para una valiosa síntesis de distintas formas de expresión de estructuras ideológicas en el discurso, véase Van Dijk (2003). 
En su dinámica, los tratamientos contribuían así, desde la producción del discurso, a la expresión de desigualdades y asimetrías sociales y étnicas, reflejando las condiciones sociohistóricas de esa producción (Fairclough, 1989). En este sentido, el sistema de tratamientos operaba -en términos de una visión crítica del discurso-, a través de las selecciones léxicas, gramaticales y pragmáticodiscursivas, como estrategias para la autopresentación positiva de Nosotros frente a Ellos (Van Dijk, 2003).

Desde el punto de vista de los españoles y sus descendientes, como actores sociales de la Colonia, estas estrategias coadyuvaron a construir, desde sus producciones discursivas, su nueva identidad en América operando entre la expresión de cortesía y la manifestación de poder. Hacia el interior del grupo, las fórmulas de tratamiento, modeladas a partir de recursos lingüísticos que ponderaban cortesía, deferencia y formalidad, constituían prácticas interlocutivas de carácter afiliativo (Bravo, 2003) al servicio de la gestión de esa identidad, construida a partir de un posicionamiento social y discursivo basado en jerarquías y distinción, que subrayaba la pertenencia grupal. Al mismo tiempo, en su atribución a los hablantes ubicados en el polo de menor poder, los tratamientos referenciales, elaborados con recursos basados solo en la individuación, se inscribían en un conjunto de estrategias discursivas de alcance social (Kaul, 2008, p. 257) producidas por el grupo de poder, que destacaban evaluaciones negativas de los aludidos, y constituían, en los discursos coloniales, prácticas descorteses de lesión de imagen (ibid.).

A partir del análisis efectuado, quedan planteadas líneas interesantes de profundización en el fenómeno abordado, tanto en la perspectiva sociolingüística como de Pragmática históricas, entre ellas, la consideración de la existencia o no de variación en las estrategias referenciales según los diferentes tipos de discursos vigentes en la Colonia, de variación pragmática en las formas alternantes asociada a la producción de tipos de actos de habla, así como de la presencia potencial de variación diacrónica a lo largo de los distintos siglos que componen dicho período histórico, abordado aquí en forma general. Al respecto, una ampliación de fuentes documentales resulta a todas luces un requisito primordial, que permita dar cuenta además -dentro de las limitaciones metodológicas que presentan los estudios sociohistóricos-, del modo en que operaban estas formas referenciales en prácticas de oralidad, tal como las que pueden ser provistas por los textos de transcripción de juicios de la época.

Es de esperar que la referida ampliación de fuentes permita dar voz precisamente a los hablantes de los grupos étnicos ubicados en el polo de menor poder, registrando sus usos, valores y sus propias representaciones sociales en relación con la composición étnica y las estructuras vigentes en la sociedad colonial.

\section{Referencias bibliográficas}

Alarcos Llorach, E. (1994). Gramática de la lengua española. Madrid, Espasa-Calpe.

Álvarez Nazario, M. (1982). Orígenes y desarrollo del español en Puerto Rico (siglos XVI y XVII). San Juan de Puerto Rico, Editorial Universitaria. 
Areces, N. (2000). Las sociedades urbanas coloniales. En Tandeter, E. (dir.), Nueva Historia Argentina, La sociedad colonial (pp. 145-187). Buenos Aires, Editorial Sudamericana.

Beato, G. (2005). La sociedad colonial. En Assadourain, C., Beato, G. y Chiaramonte, J. C. Historia Argentina. De la conquista a la independencia (pp.209-238). Buenos Aires, Paidós.

Bravo, D. (1999). ¿Imagen "positiva” vs. Imagen “negativa”?: pragmática socio-cultural y componentes de face. Oralia, 3, 21-51.

Bravo, D. (2003). Actividades de cortesía, imagen social y contextos socioculturales: una introducción. Actas del Primer Coloquio del Programa EDICE (pp. 98-108). Estocolmo, Universidad de Estocolmo.

Bravo, D. y Briz, A. (eds.) (2004). Pragmática sociocultural. Estudios sobre cortesía en español, Ariel, Barcelona.

Brown, R. y Gilman, A. (1960). The Pronouns of Power and Solidarity. En Sebeok, T. (ed.), Style in Language (pp. 253-275). New York, Massachusetts Institute of Technology.

Calsamiglia, H. y Tusón, A. (2012). Las cosas del decir. Barcelona, Ariel.

Carrera de la Red, M. (2015). Identidad, imagen y (des)cortesía en Cartagena de Indias (siglo XVII). Diálogos surgidos desde el enfrentamiento étnico. Textos en proceso, 1 (2), 206-236.

Coll,M. (2011). Las formas de tratamiento nominales usadas por y para la población de origen africano en Montevideo en los siglos XVIII y XIX. En Rebollo Couto, L. y Dos Santos Lopes, C. R. (orgs.), As formas de tratamento em portugués e em espanhol: Variação, mudança e funções conversacionais (pp. 173-213). Rio de Janeiro, Universidade Federal Fluminense.

De Granda, G. (1988). Onomástica y procedencia africana de esclavos negros en las minas del sur de la gobernación de Popayán (siglo XVIII). En Lingüistica e Historia. Temas afro-hispánicos (pp. 381422). Valladolid, Universidad de Valladolid.

Elizaincín, A., Malcouri, M. y Bertolotti, V. (1997). El español en la Banda oriental del siglo XVIII. Montevideo, Facultad de Humanidades y Ciencias de la Educación, Universidad de la República.

Ervin-Tripp, S. M. (1972). On sociolinguistic rules: Alternation and coocurrence. En Gumperz, J. y Hymes, D. (eds.), Directions in sociolinguistics. The ethnography of communication (pp. 213-250). New York, Holt, Rinehart and Winston.

Fairclough, N. (1989). Language and power. London, Longman.

Fant, L. (1989). Cultural mismatch in conversation, Spanish and Scandinavian Communicative behaviour in negotiation settings. Hermes, 2, 247-265.

Fontanella de Weinberg, M. B. (comp.) (1993). Documentos para la historia lingüística de Hispanoamérica. Siglos XVI a XVIII, Anejo LII BRAE, ALFAL, Comisión de Estudio Histórico del Español de América, Madrid, Espasa-Calpe. 
Fontanella de Weinberg, M. B. (1994). Fórmulas de tratamiento en español americano (siglos XVI y XVII). En Fontanella de Weinberg, M. B. (comp.), El español del Nuevo Mundo: Estudios sobre Historia Lingüistica Hispanoamericana (pp.7-31). Washington DC, OEA.

Goffman, E. (1967). Interactional Ritual: Essays on Face-to-Face Behavior. Nueva York, Doubleday.

Grice, H. P. (1975). Logic and conversation. En Cole, P. y Morgan. J. (eds), Studies in Syntax and Semantics III: Speech Acts (pp. 183-98). New York, Academic Press.

Gumperz, J. (ed.) (1982). Language and Social Identity. Cambridge, Cambridge University Press.

Haverkate, H. (1994). La cortesía verbal. Estudio pragmalingüistico. Madrid, Gredos.

Hernández Campoy, J. M. y Conde-Silvestre, J. C. (eds.) (2012). The Handbook of Historical Sociolinguistics. Malden, Wiley-Blackwell.

Hudson, R. A. (1981). La Sociolingüistica. Barcelona, Anagrama.

Hummel, M., Kluge, B. y Vázquez Laslop, M. E. (eds.) (2010). Formas y fórmulas de tratamiento en el mundo hispánico. México, Colegio de México, Universidad de Graz.

Joseph,J.E. (2004). Language and Identity:National, Ethnic, Religious. Basingstoke, Palgrave Macmillan.

Jucker, A. y Kopaczyk, J. (2017). Historical (im)politeness. En Culpeper J., Haugh, M. y Kádár, D. Z. (eds.), The Palgrave Handbook of Linguistic (Im)politeness (pp. 433-459). London, Palgrave Macmillan.

Kabatek, J. (2005). Tradición discursiva y cambio lingüístico. Lexis, XXIX (2), 151-170.

Kaul, S. (2008). Tipología del comportamiento verbal descortés en español. En Briz, A. et al. (eds.), Actas del III Coloquio Internacional del Programa EDICE (pp. 254-266). Valencia, Universidad de Valencia.

Klammt, K. (1999). Estudio de la aposición en documentos coloniales de Tucumán (Argentina). En Rojas Mayer. E. (ed.), Estudios sobre la historia del español de América II (pp. 145-200). Tucumán, Facultad de Filosofía y Letras, Universidad Nacional de Tucumán.

Koch, P. (2008). Tradiciones discursivas y cambio lingüístico: el ejemplo del tratamiento "vuestra merced” en español. En Kabatek, J. (coord.), Sintaxis histórica del español y cambio lingüístico: Nuevas perspectivas desde las Tradiciones Discursivas (pp. 53-88). Madrid, Iberoamericana.

Lapesa, R. (1970). Personas gramaticales y tratamiento en español. Revista de la Universidad de Madrid (Homenaje a R. Menéndez Pidal), 74, 141-167.

Levinson, S. (1989). Pragmática. Barcelona, Teide.

Maldonado, S. (2008). Las fórmulas de tratamiento en el ámbito administrativo hasta el siglo XIX. En Rojas, E. M. y Rigatuso, E. M. (orgs.), Competencia comunicativa y variedades del español en la Argentina: pasado y presente (pp. 337-48). Tucumán, SECYT-Universidad Nacional de Tucumán, Universidad Nacional del Sur. 
Maldonado, S. (2009). Acerca de las representaciones sociales del discurso colonial de los siglos XVII y XVIII (Tesis doctoral). Tucumán, Universidad Nacional de Tucumán.

Mc. Intosh, C. (1986). Common and Courtly Language: The Stylistics of Social Class in 18 th Century British Literature. Philadelphia, University of Pennsylvania Press.

Murphy, G. L. (1988). Personal reference in English. Language in Society, 17, 317-349.

Nevalainen, T.y Raumolin-Brunberg, H. (2005). Sociolinguistics and the history of English: A survey. International Journal of English Studies, 5 (1), 33-58.

Otte, E. (1982). Cartas privadas de emigrantes a Indias (1540-1616). Sevilla, Junta de Andalucía.

Presta, A. M. (2000). La sociedad colonial: raza, etnicidad, clase y género. Siglos XVI y XVII. En Tandeter, E. (dir.), Nueva historia Argentina, La sociedad colonial (pp. 55-85). Buenos Aires, Sudamericana.

Raiter, A. (2002). Representaciones Sociales. En Raiter, A. (comp.), Representaciones Sociales (pp. 5388). Buenos Aires, Eudeba.

Rebollo Couto, L. y dos Santos Lopes, C. R. (orgs.) (2011). As formas de tratamento em portugués e em espanhol: Variação, mudança e funçôes conversacionais. Rio de Janeiro, Universidade Federal Fluminense.

Rígano, M. E. (2007). Cortesía, ideología y grupos de poder. Análisis sociolingüístico del estilo cortés en el español peninsular (Siglos XII al XVII). Bahía Blanca, Universidad Nacional del Sur.

Rigatuso, E. M. (1992). Lengua, historia y sociedad. Evolución de las fórmulas de tratamiento en el español bonaerense (18301930). Bahía Blanca, Universidad Nacional del Sur.

Rigatuso, E. M. (2000). “Señora (...) ¿¿no tenés más chico?”: Un aspecto de la pragmática de las fórmulas de tratamiento en español bonaerense. Revista Argentina de Lingüistica, 16, 293-344.

Rigatuso, E. M. (2004). Fórmulas de tratamiento, políticas lingüísticas y actitudes en el español de la Argentina. El caso del español bonaerense. En Kremnitz, G. y Born, J. (comps.), Lenguas, literaturas y sociedad en la Argentina. Diálogos sobre la investigación en Argentina, Uruguay y países germanófobos [Actas del coloquio, Viena, 25-28 de marzo de 2003], Beiherfte zu Quo Vadis, Romania, 17, 197226. Viena, Editio Praesens.

Rigatuso, E. M. (2005). Las fórmulas de tratamiento del español bonaerense desde la perspectiva de la sociolingüística histórica. Factores y procesos en la dinámica de cambio (1800-1880). Analecta Malacitana, XXVIII (1), 77-100.

Rigatuso, E. M. (2006). Tratamientos y cortesía en el español bonaerense de la etapa colonial. Actas del III Coloquio Nacional de Investigadores en estudios del discurso (pp. 1-16). Bahía Blanca, Universidad Nacional del Sur.

Rigatuso, E. M. (2008). De vecinos y moradores. Tratamientos referenciales y voces para el hombre en la lengua de Buenos Aires de la etapa colonial. En Rojas, E. M.y Rigatuso, E. M. (orgs.), Competencia 
comunicativa y variedades del español en la Argentina: pasado y presente (pp. 49-87). Tucumán, SECYT, Universidad Nacional de Tucumán, Universidad Nacional del Sur.

Rigatuso, E. M. (2009). A su merced..... de su más humilde hijo. Asimetrías e identidades en construcción: fórmulas de tratamiento y cortesía verbal en el español de Buenos Aires de la etapa colonial (Discurso de incorporación como Miembro Correspondiente a la Academia Argentina de Letras). Boletin de la Academia Argentina de Letras, LXXIII, 297-298, 349-412.

Rigatuso, E. M. (2012). Expresión de interculturalidad y contacto de culturas en el sistema de tratamientos del español bonaerense. En Rojas Mayer, E. M. (ed.), Léxico e Interculturalidad. Nuevas Perspectivas (pp. 889-1009). Tucumán, Universidad Nacional de Tucumán.

Rigatuso, E. M. (2016). Nueva aproximación teórico-metodológica para el estudio de los tratamientos en el español de la Argentina. Ponencia presentada en XV Congreso de la Sociedad Argentina de Lingüística. Bahía Blanca, Sociedad Argentina de Lingüística, Universidad Nacional del Sur.

Rigatuso, E. M. y Suardíaz de Antollini, S. (coord.) (2008). Argentina: a) Buenos Aires. Siglos XVI-XVIII. En Rojas Mayer, E. M. (comp. y ed.) (2008), Documentos para la historia lingüistica de Hispanoamérica. Siglos XVI a XVIII, IV, Anejo LXI BRAE, ALFAL, Comisión de Estudio Histórico del Español de América, Madrid, Espasa-Calpe.

Ridruejo, E. (2002). Para un programa de pragmática histórica del español. En Echenique Elizondo, M. T. y Sánchez Méndez J. P. (eds.), Actas del V Congreso Internacional de Historia de la Lengua Española (pp. 159-178). Madrid, Gredos.

Rojas Mayer, E. M. (1992). Los primeros pobladores del Tucumán. Sus fórmulas de tratamiento. En España y el nuevo mundo. Homenaje de la Academia Argentina de Letras en los 500 años del encuentro de dos mundos (T. II, pp. 395-414). Buenos Aires, Academia Argentina de Letras.

Rojas Mayer, E. M. (1997). Acerca del tratamiento referencial en los documentos coloniales del Río de la Plata. Lingüistica, 9, 125-134.

Rojas Mayer, E. M. (1998). El diálogo en el español de América. Frankfurt am Main, VervuertIberoamericana.

Rojas Mayer, E. M. (2008). Las representaciones sociales en Hispanoamérica y las formas y fórmulas de tratamiento. En Rojas Mayer, E. M. y Rigatuso, E. M. (coords.), Competencia y variedades del español de la Argentina. Pasado y presente (pp. 15-31). Tucumán, SECYT-Universidad Nacional de Tucumán, Universidad Nacional del Sur.

Rojas Mayer, E. M. (2011). Las actitudes lingüísticas en la Argentina entre 1700 y 1850. Cuadernos de Ilustración y Romanticismo, 17, 1-14.

Romaine, S. (1982). Socio-bistorical linguistics. Cambridge, Cambridge University Press.

Romaine, S. (1996). El lenguaje en la sociedad. Una introducción a la sociolingüística. Barcelona, Ariel.

Rosenblat, A. (1961). Las generaciones argentinas del siglo XIX ante el problema de la lengua. Buenos Aires, Universidad de Buenos Aires. 
Rosenblat, A. (1964). Base del español de América: nivel social y cultural de los conquistadores y pobladores. Boletín de Filología, XVI, 171-230.

Spencer Oatey, H. (2008). Face, (Im)politeness and Rapport. En Spencer-Oatey, H. (ed.), Culturally Speaking. London-New York, Continuum.

Tandeter, E. (dir.) (2000). Nueva Historia Argentina. La sociedad colonial. Buenos Aires, Sudamericana.

Tannen, D. (2006). Género y discurso. Barcelona, Paidós.

Vallejos, P. (1994). Aspectos del léxico de los siglos XVI y XVII en dos regiones americanas. En Fontanella de Weinberg, M. B. (comp.), El español en el nuevo mundo: estudios sobre historia lingüistica bispanoamericana (pp. 33-60). Washington DC, OEA.

Van Dijk, T. (2003). Ideología y discurso. Barcelona, Ariel Lingüística.

Weber de Kurlat, F. (1966/67). Fórmulas de cortesía en la lengua de Buenos Aires. Filología, XII, 137192.

*Elizabeth Rigatuso es Profesora Titular de Lingüistica en el Departamento de Humanidades de la Universidad Nacional del Sur, Directora del Doctorado en Letras, Investigadora del CONICET (CEL “Dra. M.B.F.W.”), Académica Correspondiente de la Academia Argentina de Letras. Dirige el grupo EDISEBO (Estudios sobre discurso, interacción y sociedad en español bonaerense). Sus áreas de interés incluyen Sociolingüística, Lingüística histórica, Pragmática sociocultural y variacional y Discurso interaccional.

RECIBIDO: 20/11/2020

ACEPTADO: 20/12/2020 